\section{Summary}

In 30 patients with oral lichen planus regarded as severe enough to justify treatment, use of betamethasone (Betnovate) pellets $0.1 \mathrm{mg}$. was followed by substantial improvement or complete clearance of oral lesions in 20 . Seven patients showed gradual or incomplete improvement.

Only 2 out of 30 patients failed to show any response to betamethasone, but treatment was not continued for more than one month in these cases.

Of two patients with mucous membrane pemphigoid the use of betamethasone pellets was followed by complete clearance of oral lesions. A third patient showed substantial improvement until he ceased to attend.
The only side-effect of treatment was development of thrush in four patients.

The assistance of Messrs. Glaxo in their generous supply of tablets and for other help for this trial is gratefully acknowledged.

\section{REFERENCES}

Altman, J., and Perry, H O. (1961). Arch. Derm., 84, 179. Andreasen, J. O., and Pindborg, J. J. (1963). Nord. Med., 70, 861 Bratlund, H., and Holten, C. (1954). Dan. med. Bull., 1, 79. Bratlund, H., and Holten, C. (1954), Dan. med. Bull., 1, 79.
Desbrosses, J. L. (1965). Ann. Oto-laryng. (Paris), 82, 841. Friedman, M., Fletcher, J., Hinton, J. M., Lennard-Jones, J. B. Misiewicz, J. J., and Parrish, J. A. (1967). Brit. med. F., 1, 335 McCarthy, P. L., and Shklas, G. (1964). Diseases of the Oral Mucoso. New York.

Warin, R. P. (1960). Brit. 7. Derm., 72, 288.

Williams, D. I., et al. (1964). Lancet, 1, 1177

\title{
Use of Lignocaine in Treatment of Cardiac Arrhythmias
}

\author{
F. H. N. SPRACKLEN,* M.B., CH.B., M.R.C.P. ; J. J. KIMERLING,* M.B., B.S., M.R.C.P. \\ E. M. M. BESTERMAN,* M.A., M.D., F.R.C.P.; J. W. LITCHFIELD,* B.M., F.R.c.P.
}

Brit. med. F., 1968, 1, 89-91

Since the introduction of units for intensive observation and care of patients with acute myocardial infarction arrhythmias have been found in up to $70 \%$ of such natierits (Yu et al., 1965). This finding has emphasized the lack of antiarrhythmic drugs that are generally accepted as safe to use in these circumstances, especially when parenteral therapy is necessary. In acute myocardial infarction frequent ventricular ectopic beats may require treatment as urgently as the sustained ventricular arrhvthmia that they commonly preface, especially if the ectopic beats are superimposed on the $T$ wave of the preceding electrocardiographic complex (Fig. 1). Procainamide has been widely used, but the frequency of accompanying hvpotension remains a drawback to its routine use in acute myocardial infarction.

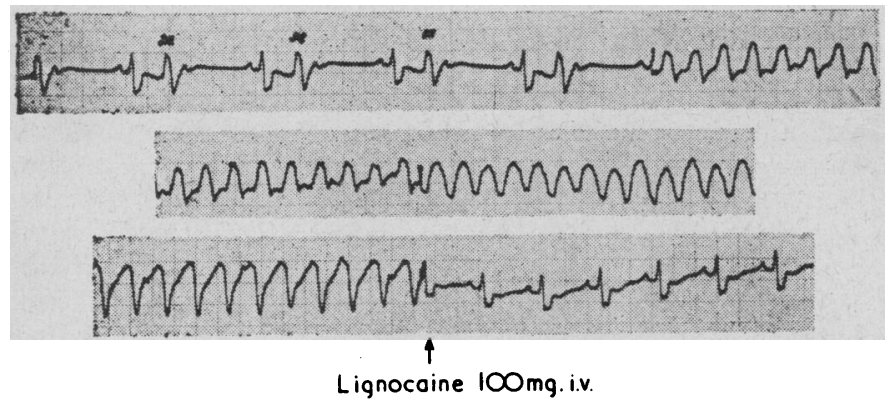

F16. 1.-Rhythm strips showing ventricular ectopic beats precipitating ventricular tachycardia ; subsequently abolished by lignocaine.

Lignocaine, which is structurally similar to procainamide, was synthesized in 1943 by Löfgren, and subsequently extensively investigated as a local anaesthetic agent (Wiedling, 1964). Southworth et al. (1950) reported the successful use of lignocaine in association with alternating-current shock in a case of ventricular fibrillation arising during cardiac catheterization. Subsequent authors have confirmed the value of lignocaine in abolishing or preventing ventricular arrhythmias in animals under a variety of experimental conditions (Van Dongen, 1953 ; Melon et al., 1953 ; Visentini, 1954 ; Frederickson and Morris, 1955 ; Cahn, 1955; Carden and Steinhaus, 1956; Harris

- Department of Cardiology, St. Mary's Hospital, London W.2. et al., 1956 ; Hitchcock and Keown, 1958 ; Austen and Moran, 1965). Greenspan et al. (1966) have shown lignocaine to be more effective than quinidine in restoring sinus rhythm in dogs with digitalis-induced ventricular arrhythmias ; Katz and Zitnik (1966) have similarly shown the superiority of lignocaine over direct-current shock in these circumstances.

In a large series of over 500 cases Hitcheock and Keown (1959) have shown the efficacy of lignocaine in the management of cardiac arrhythmias during cardiac surgery in man. This work has been confirmed by Weiss (1960). Likoff (1959) successfully used lignocaine for the control of various arrhythmias arising during surgery. De Sanctis (1965), Minuck (1965), and Bedynek et al. (1966) reported the use of lignocaine in the treatment of ventricular ectopic beats and ventricular tachycardia of non-surgical origin. It therefore appeared to be a drug worthy of further evaluation. This report is based on experience over the past year in a coronary intensive care unit, a cardiac surgical recovery ward, and the general medical wards.

\section{Material and Methods}

Fifty-five patients were treated with lignocaine for a variety of arrhythmias. The drug was usually given intravenously, though some patients received it by intramuscular injection. Initially 1-2 mg. of lignocaine per $\mathrm{kg}$. body weight was used, repeated, if necessary, every 20 minutes to a maximum of 500 mg. Subsequently it was found more satisfactory to use a "loading" dose of 1-2 mg. $/ \mathrm{kg}$. followed by the slow infusion of 1-2 mg./minute in a drip. For this purpose $500 \mathrm{mg}$. of lignocaine was added to $500 \mathrm{ml}$. of $5 \%$ dextrose in water; it was then infused at 10 to 20 drops a minute, according to the patient's response, and continued for up to 48 hours. Five hundred units of heparin was added to prevent the thrombophlebitis that commonly accompanied prolonged infusion of lignocaine into one vein.

Cardiac outputs were determined in three patients before and 10 minutes after recelving $2 \mathrm{mg}$. of lignocaine per $\mathrm{kg}$. intravenously. One had a normal heart, one a small left ventricular aneurysm, and the third a cardiomyopathy. Pulmonary artery and brachial artery pressures were recorded, and cardiac out- 
puts were determined by both indicator dilution and the Fick methods.

\section{Results in Different Arrhythmias}

(1) Sinus Tachycardia.-Lignocaine did not influence the heart rate in the three patients with sinus tachycardia in whom it was used.

(2) Supraventricular Ectopics (12 patients).-Supraventricular ectopic beats were treated in two patients after myocardial infarction, in two after open-heart surgery, and in another two after thoracotomy ; in all six cases sinus rhythm was restored by lignocaine. Six patients with frequent atrial ectopic beats following cardioversion of atrial fibrillation had their ectopics abolished by lignocaine. Despite maintenance therapy atrial fibrillation recurred in one of these patients within 12 hours.

(3) Supraventricular Tachycardia.-No obvious effect was observed in four patients with this arrhythmia.

(4) Atrial Fibrillation.-Ten patients with chronic atrial fibrillation were given lignocaine. In none of these cases was the rhythm affected.

(5) Ventricular Ectopics (18 patients).-Fourteen patients who developed ventricular ectopic beats after acute myocardial infarction were treated with lignocaine. In twelve of them the ectopics were abolished; in two they were significantly reduced (Fig. 2). Two other patients with chronic ischaemic heart disease, and long-continued ventricular ectopic beats, did not respond to lignocaine. Ventricular ectopic beats occurring in two patients after open-heart surgery were abolished by lignocaine.

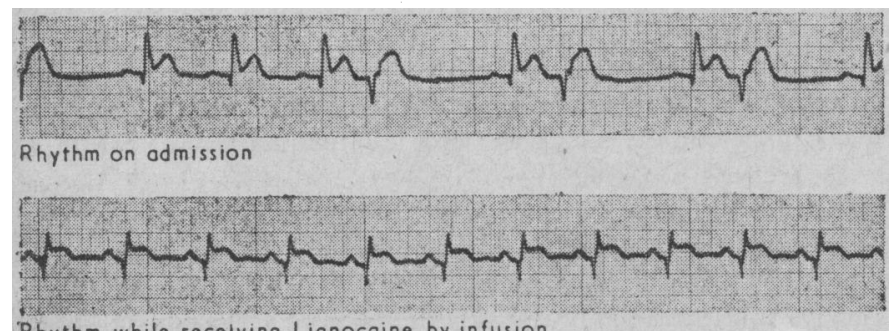

Rhythm while recelving Lignocaine by infusion

Fig. 2.- Ventricular ectopic beats after acute myocardial infarction abolished by lignocaine infusion.

(6) Ventricudar Tachycardia.-Lignocaine was successful in correcting this arrhythmia in four patients after cardiac infarction (Fig. 1). In one of them lignocaine prevented the recurrence of ventricular tachycardia. In another, with widespread ischaemic heart disease, lignocaine failed to prevent the recurrence of ventricular tachycardia. Lignocaine was used in many more instances for this arrhythmia, but usually in conjunction with cardioversion and other medication, thus making the assessment of its value in these cases difficult.

(7) Ventricular Fibrillation.-Lignocaine was used in four cases of ventricular fibrillation before any other measure. In only one case did it restore sinus rhythm. In this emergency cardioversion was attempted as soon as possible, and several drugs were usually given. Despite these other agents it was felt that in some cases lignocaine did facilitate the restoration of sinus rhythm, and it assisted in the maintenance of sinus rhythm in others.

Haemodynamic Study. - In the three patients studied lignocaine did not significantly alter the pulmonary or brachial artery pressure or cardiac output.

Side-effects.-No significant complication of lignocaine therapy was observed in any of these patients. An insignificant reduction in systolic blood pressure occurred in five patients, and dizziness, blurred vision, and drowsiness occurred in two patients receiving maximal doses of lignocaine. Local thrombophlebitis was encountered with prolonged infusion of lignocaine.
The development of this complication could be prevented by the use of small doses of heparin in the infusion.

\section{Discussion}

Lignocaine has been used by continuous intravenous infusion in anaesthetic practice (de Clive-Lowe et al., 1954). The duration of antiarrhythmic action of a single intravenous dose of $1 \mathrm{mg} . / \mathrm{kg}$. is 10 to 20 minutes. It has therefore been recommended that each dose be rapidly administered intravenously (Weiss, 1960 ; Harrison et al., 1963). However, we have found it necessary to use a loading dose of lignocaine, followed by continuous intravenous infusion, for the adequate control of arrhythmias.

Like previous authors, we have found lignocaine to be of especial value in acute ventricular arrhythmias such as those encountered after myocardial infarction and during and after cardiac surgery. In the more chronic arrhythmias and in acute supraventricular tachycardias it is of less value.

It has been reported that an excess of lignocaine may produce drowsiness, analgesia, euphoria, twitching, discomfort on breathing, speaking, or swallowing, blurred vision, sensations of heat, cold, and numbness, and sweating ; with larger doses, apprehension, disorientation, and fits may occur ; fits have been reported with doses above $750 \mathrm{mg}$./hour. With severe overdosage cardiovascular depression and respiratory arrest occur. Hypoxia increases the risk of cardiovascular toxicity. Lignocaine decreases myocardial irritability and prolongs conduction time, depolarization time, and the refractory period. Little depression of the sino-atrial node occurs. Its rapidity of action has been related to its rapid diffusion to and penetration of cell membranes (Hitchcock and Keown, 1959 ; Frieden, 1965).

Lignocaine has been found to produce no significant circulatory depression in man in doses of 1 to $2 \mathrm{mg}$. $/ \mathrm{kg}$. (Harrison et al., 1963). In fact, at this dose level Kao and Jalar (1959) demonstrated an increase in cardiac output, heart rate, stroke volume, and arterial pressure in the anaesthetized dog. These effects were shown to be due to a central action of the drug. With larger doses peripheral vasodilatation, hypotension, bradycardia, and decreased cardiac output occur. We have shown that in three patients lignocaine in a dose of $2 \mathrm{mg} . / \mathrm{kg}$. did not alter cardiac output or intravascular pressures. This drug would therefore seem to have an important advantage over other commonly used antiarrhythmic agents, propranolol, quinidine, and procainamide.

In this small series we have been impressed by the safety of lignocaine as well as by its efficacy. The mechanism of the drug's antiarrhythmic action remains unknown.

\section{Summary}

Lignocaine has been used in 55 patients suffering from a variety of arrhythmias. After a loading dose of 1 to $2 \mathrm{mg}$./ kg. it was given by continuous intravenous infusion $(0.1 \%)$. It was found to be particularly successful in treatment of acute ventricular arrhythmias, notably those occurring after acute myocardial infarction, during and after cardiac surgery, and in the treatment of atrial ectopic beats, though of less value in sustained atrial arrhythmias.

Since the completion of this report the value of lignocaine in these circumstances has been supported at a W.H.O. meeting in Edinburgh (Annotation, Lancet, 1967).

\section{REFERENCES}

Austen, W. G., and Moran, J. M. (1965). Amer. F. Cardiol., 16, 701. Bedynek, J. L., Weinstein, K. N., Kah, R. E., and Minton, P. R. (1966). 7. Amer. med. Ass., 198, 553.

Cahn, J. (1955). Cited by Wiedling (1964). 
Carden, N. L., and Steinhaus, J. E. (1956). Circulat. Res., 4, 680. de Clive-Lowe, S. G., Gray, P. W. S., and North, J. (1954). Anaesthesia, 9. 96.

De Sanctis, R. W. (1965). 7. Amer. med. Ass., 191, 632

Frederickson, E. L., and Morris, L. E. (1955). Fed. Proc., 14, 340.

Frieden, J. (1965). Amer. Heart \%. 70, 713 .

Freenspan, K., Lord, T. J., Steinmetz, E. F., and Fisch, C. (1966). 7. Indiana med. Ass., 59, 148.

Harris, A. S., Aguirre y Guerra, C., Liptak, R. A., and Brigham, J. C. (1956). \%. appl. Physiol., 8, 499.

Harrison, D. C., Sprouse, J. H., and Morrow, A. G. (1963). Circulation, 28,486 .

Hitchcock, P., and Keown, K. K. (1958). Fed. Proc., 17, 378.

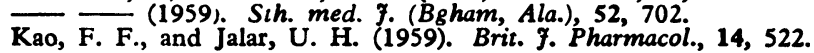

Katz, M. J., and Zitnik, R. S. (1966). Amer. 7. Cardiol., 18, 552.

Lancet, 1967, 2, 665

Likoff. W. (1959). Amer. 7. Cardiol., 3, 427.

Melon, J. M., Cahn, J., and Dubrasquet, M. (1953). Cited by Wiedling (1964)

Minuck M. (1965) Canad med. Ass, 7., 92, 16.

Southworth J. L., McKusick, V. A., Pierce, E. C., and Rawson, F. L. (1950). F. Amer. med. Ass., 143, 717

Van Dongen, K. (1953). Arch. int. Pharmacodyn., 96, 45.

Visentini, P. (1954). Cited by Wiedling (1964).

Weiss W. A. (1960). Anesth. Analg. curr. Res., 39, 369

Wiedling, S. (1964). Xylocaine : The Pharmacological Basis of its Clini-

Yu, P. N., Fox, S. M., Imbodrn, C. A., and Killip, T. (1965). Mod. Conc. cardiovasc Dis., 34, 27.

\title{
Follow-up Study of Refractory Obesity Treated by Fasting
}

\author{
A. C. MACCUISH,* M.B., CH.B. ; J. F. MUNRO,* M.B., M.R.C.P.ED. ; L. J. P. DUNCAN,* M.B., B.SC., F.R.C.P.ED.
}

Brit. med. F., 1968, 1, 91-92

The treatment of obesity by a period of fasting in hospital has achieved popularity since its introduction by Bloom in 1959 , and the few reports of its long-term effects have been encouraging (Hunscher, 1966 ; Harrison and Harden, 1966). We present the follow-up results of fasting in patients having "refractory" obesity in whom this form of treatment has not previously been specifically studied; these are not encouraging.

\section{Materials and Methods}

The Table includes the relevant pretreatment data of the 25 patients studied. All were clinically obese, overweight by at least $40 \%$ of their standard (U.S.A. Medico-Actuarial Investigation 1912), and satisfied the criteria for refractory obesity as originally defined (Duncan et al., 1960). Thus all had regularly attended the department, but their weight had either increased or remained unchanged during the six months before inpatient fasting despite the use of anorectic agents in

- Diabetic and Dietetic Department, Royal Infirmary of Edinburgh. nine subjects. All were shown by appropriate investigation to be free from endocrine disease, none was in cardiac failure, but several had complications of obesity, such as hernia, osteoarthritis, varicose veins, or flat feet.

On admission to hospital patients were given a 400-500calorie diet for one or two days. During the subsequent fast they were allowed to drink as much water, unsweetened black coffee or tea, or acaloric fruit juices or cordial as they wished, but no solid food was permitted. A vitamin preparation (Multivite) was given routinely and mineral supplements, hypnotics, and sedatives if required. Patients were weighed every second day and encouraged to be ambulant. Estimations of the blood electrolytes, bicarbonate, and uric acid and urine tests for ketones were regularly made, but no serious biochemical changes occurred and no patient had to terminate the fast prematurely. For a few days before leaving hospital each patient took a daily diet of 400 calories. At the time of discharge all were given further instruction in an appropriate 400-1,000-calorie daily diet and were weighed in the outpatient department wearing normal clothing; this weight was taken as the weight on discharge.

Weight Data of Fasted Patients

\begin{tabular}{|c|c|c|c|c|c|c|c|c|c|c|c|c|c|c|c|c|}
\hline \multirow{2}{*}{$\begin{array}{l}\text { Case } \\
\text { No. }\end{array}$} & \multirow{2}{*}{ Age } & \multirow{2}{*}{ Sex } & \multirow{2}{*}{$\begin{array}{c}\text { Stan- } \\
\text { dard } \\
\text { Weight } \\
\text { (lb.) }\end{array}$} & \multicolumn{2}{|c|}{$\begin{array}{l}\text { Excess Weight } \\
\text { (1b.) Before Fast }\end{array}$} & \multicolumn{2}{|c|}{$\begin{array}{l}\text { Excess Weight } \\
\text { At Start of Past }\end{array}$} & \multirow{2}{*}{$\begin{array}{l}\text { Time } \\
\text { Fasted } \\
\text { (Days) }\end{array}$} & \multirow{2}{*}{$\begin{array}{l}\text { Weight } \\
\text { Lost } \\
\text { During } \\
\text { Fast } \\
\text { (lb.) }\end{array}$} & \multicolumn{4}{|c|}{ Bxcess Weight After Fast } & \multirow{2}{*}{$\begin{array}{l}\text { Follow-up } \\
\text { Period } \\
\text { (months) }\end{array}$} & \multirow{2}{*}{$\begin{array}{c}\text { Weight } \\
\text { Change } \\
\text { Since End } \\
\text { of Fast } \\
\text { (lb.) }\end{array}$} & \multirow{2}{*}{$\begin{array}{c}\text { Latest } \\
\text { Weight } \\
\text { as Change } \\
\text { Fromge } \\
\text { Weight } \\
\text { Before } \\
\text { Fast }\end{array}$} \\
\hline & & & & $\begin{array}{c}6 \\
\text { months }\end{array}$ & ${ }^{3}$ & lb. & standard & & & \begin{tabular}{|c|} 
Immed- \\
iately
\end{tabular} & $\begin{array}{c}3 \\
\text { months }\end{array}$ & $\begin{array}{c}6 \\
\text { months }\end{array}$ & $\begin{array}{l}\text { When } \\
\text { Last } \\
\text { Seen }\end{array}$ & & & \\
\hline $\begin{array}{r}1 \\
2 \\
3 \\
4 \\
5 \\
5 \\
6 \\
7 \\
8 \\
9 \\
10 \\
11 \\
12 \\
13 \\
14 \\
15 \\
116 \\
17 \\
18 \\
19 \\
20 \\
21 \\
22 \\
23 \\
24 \\
25\end{array}$ & $\begin{array}{l}24 \\
48 \\
30 \\
57 \\
38 \\
45 \\
20 \\
43 \\
61 \\
55 \\
20 \\
37 \\
38 \\
62 \\
51 \\
50 \\
45 \\
40 \\
51 \\
50 \\
53 \\
37 \\
43 \\
33 \\
39\end{array}$ & $\begin{array}{l}\mathbf{F} \\
\mathbf{P} \\
\mathbf{M} \\
\mathbf{P} \\
\mathbf{M} \\
\mathbf{P} \\
\mathbf{P} \\
\mathbf{P} \\
\mathbf{P} \\
\mathbf{P} \\
\mathbf{P} \\
\mathbf{P} \\
\mathbf{M} \\
\mathbf{P} \\
\mathbf{P} \\
\mathbf{P} \\
\mathbf{F} \\
\mathbf{P} \\
\mathbf{F} \\
\mathbf{P} \\
\mathbf{F} \\
\mathbf{P} \\
\mathbf{F} \\
\mathbf{P} \\
\mathbf{F} \\
\mathbf{M}\end{array}$ & $\begin{array}{l}139 \\
144 \\
160 \\
144 \\
159 \\
146 \\
1129 \\
141 \\
136 \\
145 \\
1141 \\
154 \\
132 \\
136 \\
117 \\
134 \\
159 \\
134 \\
149 \\
148 \\
149 \\
137 \\
130 \\
170\end{array}$ & $\begin{array}{r}61 \\
59 \\
224 \\
90 \\
77 \\
209 \\
81 \\
114 \\
169 \\
108 \\
102 \\
115 \\
110 \\
64 \\
178 \\
265 \\
73 \\
132 \\
159 \\
78 \\
111 \\
101 \\
121 \\
67 \\
214\end{array}$ & $\begin{array}{r}65 \\
60 \\
227 \\
93 \\
77 \\
209 \\
85 \\
116 \\
168 \\
112 \\
104 \\
118 \\
118 \\
64 \\
181 \\
267 \\
79 \\
130 \\
159 \\
78 \\
119 \\
110 \\
121 \\
710 \\
218\end{array}$ & $\begin{array}{r}61 \\
60 \\
230 \\
94 \\
78 \\
209 \\
81 \\
119 \\
176 \\
115 \\
106 \\
120 \\
124 \\
64 \\
179 \\
272 \\
83 \\
134 \\
159 \\
955 \\
129 \\
114 \\
121 \\
73 \\
240\end{array}$ & $\begin{array}{r}43 \\
42 \\
144 \\
65 \\
49 \\
143 \\
62 \\
86 \\
130 \\
79 \\
75 \\
78 \\
94 \\
47 \\
153 \\
203 \\
52 \\
100 \\
107 \\
69 \\
90 \\
77 \\
88 \\
56 \\
141\end{array}$ & $\begin{array}{l}18 \\
12 \\
40 \\
31 \\
34 \\
40 \\
12 \\
26 \\
21 \\
23 \\
17 \\
21 \\
27 \\
29 \\
16 \\
32 \\
16 \\
15 \\
26 \\
36 \\
27 \\
34 \\
10 \\
16 \\
17\end{array}$ & $\begin{array}{l}23 \\
12 \\
58 \\
43 \\
35 \\
33 \\
9 \\
22 \\
24 \\
24 \\
21 \\
32 \\
28 \\
13 \\
19 \\
42 \\
22 \\
22 \\
18 \\
34 \\
26 \\
31 \\
20 \\
16 \\
20\end{array}$ & $\begin{array}{r}38 \\
48 \\
172 \\
51 \\
43 \\
176 \\
72 \\
997 \\
152 \\
91 \\
85 \\
88 \\
96 \\
51 \\
160 \\
230 \\
61 \\
112 \\
141 \\
61 \\
103 \\
83 \\
101 \\
577 \\
220\end{array}$ & $\begin{array}{r}\overline{56} \\
168 \\
55 \\
55 \\
184 \\
79 \\
103 \\
168 \\
107 \\
87 \\
75 \\
110 \\
59 \\
175 \\
238 \\
46 \\
125 \\
144 \\
72 \\
113 \\
89 \\
105 \\
91 \\
219\end{array}$ & $\begin{array}{r}- \\
202 \\
63 \\
68 \\
186 \\
81 \\
109 \\
164 \\
121 \\
89 \\
79 \\
126 \\
64 \\
177 \\
248 \\
46 \\
131 \\
159 \\
72 \\
117 \\
103 \\
111 \\
99 \\
240\end{array}$ & $\begin{array}{r}\overline{-} \\
217 \\
66 \\
71 \\
195 \\
82 \\
123 \\
168 \\
123 \\
107 \\
92 \\
132 \\
67 \\
191 \\
266 \\
78 \\
136 \\
161 \\
100 \\
133 \\
113 \\
121 \\
105 \\
321\end{array}$ & $\begin{array}{c}\bar{Z} \\
\overline{7} \\
8 \\
8^{*} \\
8 \\
10 \\
10 \\
10^{*} \\
11^{*} \\
12 \\
12^{*} \\
12^{*} \\
14^{*} \\
14^{*} \\
18 * \\
19 \\
21 \\
22 \\
22^{*} \\
23 \\
24\end{array}$ & $\begin{array}{l}\bar{z} \\
+45 \\
+15 \\
+28 \\
+19 \\
+10 \\
+26 \\
+16 \\
+32 \\
+22 \\
+4 \\
+36 \\
+16 \\
+31 \\
+36 \\
+17 \\
+24 \\
+20 \\
+39 \\
+30 \\
+30 \\
+20 \\
+48 \\
+101\end{array}$ & $\begin{array}{l}= \\
-13 \\
-28 \\
=28 \\
-7 \\
-14 \\
+1 \\
+4 \\
-8 \\
+8 \\
+1 \\
+28 \\
+8 \\
+3 \\
+12 \\
+6 \\
-6 \\
-5 \\
+2 \\
+2 \\
+5 \\
+4 \\
-1 \\
\pm 0 \\
+32 \\
+81\end{array}$ \\
\hline
\end{tabular}

